\title{
URBANISMO
}

ISSN 0717-5051

Revista de Urbanismo N²9 - Diciembre de 2013

http://revistaurbanismo.uchile.cl

\section{Fondos inmobiliarios y riesgo urbano ${ }^{1}$}

Real estate funds and urban risk

\section{Antonio Daher}

\section{Filiación}

Instituto de Estudios Urbanos y Territoriales y Centro de Desarrollo Urbano Sustentable, CEDEUS

E mail: adaher@uc.cl

\section{Resumen}

La relación entre fondos de inversión inmobiliaria y riesgo urbano es compleja: el riesgo del sector inmobiliario-financiero incrementa la vulnerabilidad urbana, y la sustentabilidad de las ciudades es más dependiente del riesgo de ese sector que éste del riesgo urbano y del riesgo país. La suerte de las economías nacionales está muy asociada a la suerte de las ciudades y la del riesgo supranacional global a la del riesgo subnacional urbano. El riesgo financieroinmobiliario se ha multiplicado por la financiarización: los fondos inmobiliarios transnacionales y la gran movilidad geográfica de capitales, por su alta y selectiva concentración metropolitana, inducen la inflación de burbujas y las crisis, afectando la sustentabilidad urbana, nacional e incluso global. La financiarización no sólo es inmobiliaria: se trata de una amplia "financiarización urbana" que incluye -como en la crisis subprime- la vivienda social, y que agudiza las disparidades e inequidades territoriales.

\section{Palabras claves}

Fondos inmobiliarios; riesgo urbano; sustentabilidad urbana.

\begin{abstract}
The association between real estate funds and urban risk is complex; financial uncertainty of real estate development increases urban vulnerability and negatively affects the sustainability of cities. However, the relation is not reciprocal, since the impact that urban risk, and the reliability of national economies have on real estate development is relatively low. The success of national economies depends on the specific conditions of a country's cities, and the success of global supranational risk is closer to urban subnational risk. The financial risk of real estate development has increased because of financialisation. As the metropolitan concentration is high and selective, transnational real estate funds, along with the geographical mobility of capital, propel the growth of real estate bubbles and crisis, making a big impact on sustainability at many levels - urban, national and even global-. Financialisation is not just a real estate development issue; rather it is an 'urban financialisation' (like the subprime crisis), which includes social housing, intensifying territorial disparities.
\end{abstract}

Key words

Real estate funds; urban risk; urban sustainability.

\section{Sumario}

Introducción

1 Movilidad de capitales, financiarización, burbujas y riesgo

2 Metropolización de los fondos inmobiliarios y sustentabilidad urbana.

Conclusiones

${ }^{1}$ Proyecto FONDAP 15110020. Pontificia Universidad Católica de Chile 
Bibliografía

\section{Introducción}

¿Qué relación existe entre los fondos de inversión inmobiliaria y el riesgo urbano? En principio podría suponerse que los primeros buscan diversificar el riesgo en sus colocaciones de capital, distribuyéndolas geográficamente entre múltiples ciudades de variados países, minimizando así el riesgo de sus carteras de inversión. También podría argüirse que en esa selección geográfica los fondos evitarán centros urbanos de países muy riesgosos económica, social o políticamente, excepto si la rentabilidad fuere muy atractiva. En ambos casos el riesgo se percibe como exógeno. Si bien lo anterior tiene cierta validez, aquí se planteará que la propia conducta territorial de los fondos inmobiliarios no pocas veces los hace concomitantemente responsables, en importante medida y junto a otros factores, del incremento del riesgo, en este caso también endógeno. En otras palabras, no sólo los fondos y sus inversiones inmobiliarias pueden resultar afectados por condiciones socioeconómicas y políticas inherentes a los centros urbanos y metropolitanos -el "riesgo urbano" dentro del riesgo país- sino que las propias ciudades, sus economías y su estabilidad sociopolítica resultan muchas veces vulnerables a la acción de los fondos, es decir, al "riesgo inmobiliario". Los países y ciudades, compitiendo a menudo por atraer capitales e inversiones inmobiliarias para incrementar su crecimiento económico, terminan con cierta regularidad en crisis detonadas por burbujas inmobiliarias y fuga de capitales. Esto último -siempre junto a otros factores locales e internacionales, como se argumentará luego- podrá desestabilizar a las economías nacionales en su conjunto, detonando y contagiando incluso crisis más o menos globales.

En efecto, "La burbuja en el mercado de la vivienda es una de las causas más importantes, por no decir la causa principal, de la crisis"2. "La burbuja del sector inmobiliario estadounidense (...) ocupa el centro del escenario como culpable de la más reciente crisis financiera mundial" ${ }^{3}$. Las grandes crisis vinculadas a burbujas inmobiliarias y a la creciente financiarización de la ciudad inducen a una reformulación de los problemas asociados a la concentración y metropolización de los fondos inmobiliarios, los que afectan y alteran críticamente los procesos y las lógicas urbanas y territoriales, con graves impactos sociales y nuevas demandas a las políticas públicas y la planificación de ciudades y territorios; afectando también y en consecuencia la sustentabilidad económica y, en extremo, política de ciudades, regiones y países completos. Este artículo, relacionando los fondos inmobiliarios y el riesgo urbano, tiene como propósito considerar algunos de los factores de las transformaciones urbano- territoriales propias de tales procesos y, más específicamente, de las crisis financiero-inmobiliarias relacionadas a los mismos.

La progresiva urbanización de la población y la economía y la creciente concentración de los sectores y actores inmobiliarios y financieros en las grandes áreas metropolitanas ayudan a comprender la relación de los ciclos inmobiliarios y sus burbujas con las crisis económicas, por la alta influencia macroeconómica del sector inmobiliario, y su función articuladora entre el sector financiero y múltiples sectores de la economía real.

Las instituciones bancarias y financieras, y los fondos de inversión inmobiliaria transnacionales, descubrieron en la financiarización, titulización y securitización una innovación eficaz y funcional a sus requerimientos de diversificación geográfica y dispersión del riesgo

2 SHILLER, 2009: p.33

3 REINHART y ROGOFF, 2011: p.18 
hipotecario. Esa nueva ingeniería terminó siendo también eficaz como medio expedito de contagio de una crisis con ubicuidad financiera, pero no social ni territorial ${ }^{4}$.

Como el crecimiento y el desarrollo son procesos altamente localizados y concentrados, la aparente ubicuidad financiera se comprobará más bien como amplia movilidad geográfica de capitales no excluyente de su alta concentración territorial.

La relación entre el sector inmobiliario y la macroeconomía se ilustra nítidamente por algunos autores: Stiglitz ${ }^{5}$ afirma que aproximadamente dos terceras o tres cuartas partes de la economía de los Estados Unidos estaban relacionados con la vivienda, mientras que Shiller ${ }^{6}$ sostiene, complementariamente, que "el mercado inmobiliario es uno de los activos más importantes, comparable en tamaño a todo el mercado de valores". La gran ponderación macroeconómica de la economía inmobiliaria reafirma aún más las constataciones anteriores. Dada su fuerte contribución al PIB y su importante participación en la inversión y por su amplia incidencia en el empleo y en el gasto, el sector inmobiliario detenta un peso económico estratégico. Ya que, como aconteció en la última década, la inversión privada en vivienda representó más de un tercio de la inversión privada total estadounidense ${ }^{7}$ y puesto que el sector vivienda explicó cerca del cincuenta por ciento del incremento del PIB de ese país ${ }^{8}$, entonces se comprende mejor la magna incidencia macroeconómica del sector inmobiliario. "¿Podría el sector financiero ser poco vulnerable - incluso sin la titulización - a tamaña realidad? ¿Podrían las crisis bancarias- antes y después de la titulización - no estar relacionadas con los ciclos inmobiliarios? ¿Podrían ser tales crisis menos agudas, más breves y menos graves de lo que han resultado ser?"9. Y más aún, ¿podrían ser las economías nacionales e incluso la global sustentables frente al riesgo financiero-urbano?

Puesto que la deuda hipotecaria alcanzó a ser casi igual al PIB de la mayor economía mundial ${ }^{10}$; dado que los créditos garantizados con hipotecas superaron a su déficit en cuenta corriente ${ }^{11}$; y ya que el volumen total de títulos, incluidos los inmobiliarios, llegó a ser equivalente al de los bonos del Tesoro de EE.UU ${ }^{12}$, se entiende mejor la amplia vulnerabilidad del ámbito financiero frente a las burbujas y variaciones cíclicas del sector inmobiliario, y también la mayor severidad y elongación de las crisis inducidas por él. Con relación a esta exposición al riesgo, Marichal ${ }^{13}$, aludiendo a los impactos de la crisis hipotecaria del 2008 en las plazas financieras más dinámicas, Nueva York y Londres, y recurriendo a una expresión de Cassis, se interrogaba por los factores comunes que desestabilizaron estas "capitales del capital", haciéndolas vulnerables y afectando su sustentabilidad (aún hoy, cinco años después de la crisis...)

Sea por desregulación o injerencia del Estado, la economía urbana y la inmobiliaria aparecen en cualquier caso, directa o indirectamente, muy asociadas a la metropolización del producto y de las finanzas, y a sus procesos de auge y caída. La a-espacialidad atribuida a la financiarización no desterritorializa ni deslocaliza esos procesos, antes bien los concentra geográficamente metropolizándolos selectivamente. Por ello, la economía y sus crisis tienen focos y epicentros metropolitanos en medio de la globalización.

4 DAHER, 2013a y 2013b

5 STIGLITZ, 2010

${ }^{6}$ SHILLER, 2009: p.121

7 FOSTER y MAGDOFF, 2009

8 SOROS, 2008

9 DAHER, 2013a: p.70

10 FOSTER y MAGDOFF, 2009

${ }^{11}$ SOROS , 2008

12 ATTALI, 2009

13 MARICHAL, 2010 
Este artículo está basado en dos anteriores, a los que complementa: "El sector inmobiliario y las crisis económicas"14 y Territorios de la financiarización urbana y de las crisis inmobiliarias"15. El texto se desarrolla en dos secciones: la primera trata de la financiarización y la movilidad geográfica de capitales, como asimismo de la inflación de burbujas inmobiliarias y del riesgo de crisis y su contagio. La segunda sección está referida a la metropolización de los fondos de inversiones, incluidos los de pensiones y más específicamente los inmobiliarios, verificando su sesgo concentrador y sus consecuencias de inequidad socio-territorial.

\section{Movilidad de capitales, financiarización, burbujas y riesgo}

¿Cómo "modernizar" las muy tradicionales y "seguras" inversiones inmobiliarias en la época de la globalización económica y la instantaneidad financiera? ¿Cómo incorporar los magnos patrimonios en bienes raíces a las nuevas dinámicas y lógicas propias de la casi ilimitada movilidad de capitales? ¿De qué manera podrían multiplicarse las rentabilidades inmobiliarias? ¿Cómo obtener mayores beneficios de las hipotecas y, a la vez, disminuir su riesgo? Un desafío casi sin solución para muchos era lograr a "movilidad" del capital inmobiliario, y la "liquidez" de un capital como aquel, físico y fijo, casi por definición no transable ni perfectamente divisible. Lo logró la financiarización, transformando esos activos reales en financieros -líquidos y móviles - aptos ahora para ser transables en los mercados de valores ${ }^{16}$. Es más, su gran volumen de inversiones afectó los precios y la orientación del resto de los capitales ${ }^{17}$.

Ciertamente la financiarización une los mercados, haciendo comparables sus productos e incrementando la competencia. Pero también aumenta la concentración del capital, las inversiones y el poder económico en las grandes metrópolis. Ello puede generar y agudizar una burbuja inmobiliaria ${ }^{18}$. La movilidad territorial de capitales a nivel global ${ }^{19}$ se ha constituido como uno de los factores que tienen un efecto precio en los activos inmobiliarios y bursátiles ${ }^{20}$, y que contribuyen a la inflación de burbujas ${ }^{21}$. Esto se pudo constatar en la crisis subprime en Estados Unidos 22 ; también en la crisis del sudeste asiático ${ }^{23}$; y en el boom inmobiliario a mediados del 2000 en Brasil24.

Por cierto las crisis económicas detonadas por las burbujas inmobiliarias y la financiarización urbana afectan crítica y diferencialmente a ciudades y regiones, confirmando la vigencia y relevancia de su territorialidad pese a la presunta ubicuidad inherente a la financiarización. Esta no desterritorializa los procesos de crecimiento y recesión. Más aún, los concentra geográficamente y los metropoliza selectivamente. Tanto la economía como sus crisis están fuertemente asentadas y focalizadas en los centros metropolitanos. En consecuencia, el riesgo, la vulnerabilidad y la sustentabilidad de las economías nacionales y de la propia economía global se evidencian hoy como indisociables de las grandes metrópolis.

La fuerte incidencia metropolitana en la economía se registra en una nueva publicación -entre muchas-que indica que en las 259 grandes ciudades donde habita el $80 \%$ de la población estadounidense se genera aproximadamente el $85 \%$ del producto interno bruto del país. El mismo estudio prevé que aportarían más del $10 \%$ del incremento global del producto mundial

\footnotetext{
14 DAHER, 2013a

15 DAHER, 2013b

16 THEURILLAT, 2009

17 LORRAIN, 2008

18 THEURILLAT et al, 2010

19 KRUGMAN, 2010; REINHART y ROGOFF, 2011

20 ROUBINI Y MIHM, 2010

${ }^{21}$ SHILLER, 2009; STIGLITZ, 2010

22 ROUBINI y MIHM, 2010

23 HIANG LIOW, 2008

24 ZANIN, 2011
} 
de 2025 , dentro de un grupo de 600 ciudades de variados países que contribuirían con el $60 \%$ del crecimiento del mismo en esa fecha25. Por cierto esta "metropolización del PIB" resultará determinante en la orientación de la inversión del sector inmobiliario.

Pero no puede generalizarse: las áreas metropolitanas, compartiendo elementos comunes, distan de ser homogéneas. La heterogeneidad de las diversas metrópolis y la propia competencia entre ellas obliga a una estrategia selectiva de diversificación territorial de los fondos de inversión inmobiliaria y también de los otros fondos institucionales. Esta selección espacial afectará desigualmente el desarrollo urbano. En medio de la globalización, las instituciones financieras invierten en grandes proyectos metropolitanos - sólo en determinadas áreas o zonas - correlacionando las inversiones con la jerarquía de las ciudades ${ }^{26}$.

El rol articulador del sector inmobiliario entre el sector financiero y la economía real influye en la colocación de inversiones de los fondos inmobiliarios, fondos de pensiones y de seguros, fondos soberanos y de otros agentes institucionales, en bienes raíces, inmuebles (oficinas, edificios comerciales, viviendas) e infraestructura de diversos sectores. Tales fondos institucionales inciden así con fuerza y selectivamente en los mercados, en los precios inmobiliarios y en el desarrollo urbano en general. Los fondos de inversión inmobiliaria intermedian varias de esas colocaciones de capital, diversificando los portafolios y en principio -y sólo en principio- minimizando los riesgos de los inversionistas. El número y volumen de tales fondos ha crecido exponencialmente a nivel global, especializándose algunos de ellos sectorialmente, aunque siempre con una marcada concentración en una o pocas ciudades principales ${ }^{27}$. En efecto, en una de las investigaciones pioneras sobre los fondos de inversión inmobiliaria, Daher ${ }^{28}$ verificó su fuerte tendencia concentradora sectorial y territorial en el caso chileno, con un claro sesgo metropolitano y hacia las comunas de mayores ingresos.

Entre los diversos fondos de inversión, los de pensiones han llegado a ser en uno de los principales agentes en los mercados inmobiliarios y sus colocaciones resultan decisivas sectorial y territorialmente. También ellos, por su tendencia concentradora, acrecientan las disparidades con efectos en la economía real y en su geografía ${ }^{29}$. La financiarización de la mayoría de los fondos de inversión contribuye, atendida la orientación geográfica de sus inversiones, a una clara inequidad regional, y en el caso de los fondos de pensiones, a una paradojal regresividad social.

La dialéctica entre real concentración y dispersión virtual de las inversiones inmobiliarias resulta ser una clave en la reinterpretación y reevaluación de los conceptos tradicionales de riego. En efecto, "La titulización, fragmentando, atomizando y dispersando el riesgo hipotecario ${ }^{30}$ lo minimiza para algunos y lo endosa e incrementa para muchos, potenciando un efecto contagio inconmensurable. La filosofía de "originar para mantener" fue sustituida, con la titulización, por la de "originar para distribuir"31. La gran sofisticación financiera conduce tanto a una dilución de los riesgos como también a su difusión en períodos de crisis ${ }^{32 " 33}$.

Las crisis reiteradamente han demostrado la limitación del concepto de riesgo - país. El riesgo es cada vez más inherente a regiones supranacionales. La globalización y los tratados y acuerdos de libre comercio y de integración regional incrementan la vulnerabilidad al hacer más

\footnotetext{
25 MANYIKA et. al., 2012

26 THEURILLAT, 2009

27 LE FUR, 2006

28 DAHER, 1995a

29 THEURILLAT et al, 2010

30 ROUBINI y MIHM, 2010; STIGLITZ, 2010

${ }^{31}$ ROUBINI Y MIHM, 2010

32 LORRAIN, 2008

33 DAHER 2013 b: p.16-17
} 
abiertas las economías y desdibujar las fronteras ${ }^{34}$. El riesgo supranacional, sin embargo, está fuertemente asociado -como se ha dicho- a determinados espacios subnacionales conocidos comúnmente como áreas y regiones metropolitanas.

El riesgo -en sus distintas escalas territoriales- y la especulación están ciertamente relacionados:

\begin{abstract}
"Hay activos que son objeto de apalancamiento y precios especulativos. En la crisis subprime, lo fueron no solo el suelo y los inmuebles, sino también los "exóticos títulos" hipotecarios ${ }^{35}$. Es decir, la especulación y el apalancamiento afectó a activos reales y, además, a los activos o "derivados" financieros de aquellos. Las prácticas de "slicing and dicing" (titulización), las collateralised debt obligations (CDO), los credit default swaps (CDS), las residential mortgage-backed securities (RMBS), los equity o loss money, las "hipotecas con trampa", las subprime, los "préstamos del mentiroso" (ALT-A) y los créditos "ninja" (no job, no income, no assets) ilustran emblemáticamente la simbiosis entre innovaciones de ingeniería financiera, segregación social crediticia y riesgo moral inherente a estas modalidades de financiarización y al "sistema bancario en la sombra"". ${ }^{36}$
\end{abstract}

Como ya se ha señalado, uno de los más eficaces ingenios financieros para licuar lo ilíquido y mover lo inmóvil fue la titulización inmobiliaria, que acrecentó casi sin límites ni barreras la transabilidad hipotecaria ${ }^{37}$ como también la liquidez de activos con costos altos de transacción. La titulización, incrementando su transabilidad y liquidez, financiarizó al sector inmobiliario a la vez que "inmobiliarizó al sector financiero"38.

La especulación y el apalancamiento financiero, y ciertamente las burbujas, influyen significativamente en los ciclos inmobiliarios y estos, a su vez, en las crisis. En efecto, "Ios ciclos de precios de la vivienda, y más ampliamente del sector inmobiliario, han estado directa y recurrentemente relacionados con las crisis bancarias y financieras ${ }^{39}$. El factor inmobiliario ha sido el detonante de las crisis más severas desde la segunda mitad del siglo $\mathrm{XX}^{40}$. Los ciclos recesivos inmobiliarios prácticamente duplican en duración a los bursátiles ${ }^{41}$ y suelen tener un mayor impacto financiero, en la inversión, el empleo y el consumo. Reconocer que los ciclos de precios inmobiliarios se relacionan directamente con las crisis bancarias y financieras, y que las burbujas inmobiliarias están en el centro de las crisis, equivale a reconocer que las burbujas y crisis se incuban en las ciudades $y$, sobre todo, en la metrópolis, sedes del capital inmobiliario"42. Pero ciertamente éstas no sólo están en el origen de las crisis, además son las principales receptoras -aunque no las únicas- de muchos de sus graves y dolorosos efectos. Una muy desigual resiliencia de las ciudades frente a los efectos de las crisis y los tiempos muy variados de superación de sus periodos recesivos se asocian a las asimetrías y asincronías entre metrópolis en acusar los impactos de las mismas.

Más allá de los efectos en las redes y nodos urbanos, las crisis influyen también en catalizar cambios radicales en la externalización, deslocalización y relocalización productiva entre naciones. Según Fumagalli ${ }^{43}$ la crisis actual acabaría con la hegemonía financiera de Occidente

34 DAHER, 2004

35 ROUBINI Y MIHM, 2010

36 DAHER, 2013b: p.26

37 RAMONET, 2009; ROUBINI y MIHM, 2010

38 DAHER, 2013a: p.47

39 LAEVEN y VALENCIA, 2008; ROUBINI y MIHN, 2010

40 RAMONET, 2009; REINHART y ROGOFF, 2011

${ }^{41}$ REINHART Y ROGOFF, 2011

42 DAHER, 2013b: p.26-27

43 FUMAGALLI, 2011b 
y a la primacía de Oriente en la "economía real" como en el comercio internacional. Desde otra perspectiva, puede agregarse que la crisis en la Zona Euro y la cuestionada sustentabilidad de la integración europea muestran el conflicto de intereses entre los países "periféricos" y las menos vulnerables economías del centro norte del continente. Las consecuencias económicas, sociales y políticas de la crisis se hacen allí más dramáticas en su "discriminación geográfica", ahora entre naciones y no sólo entre espacios subnacionales.

\section{Metropolización de los fondos inmobiliarios y sustentabilidad urbana.}

La "financiarización inmobiliaria y urbana", como medio de ampliación de la movilidad espaciotemporal de los capitales y, por ende, de globalización de los mismos, se nutre ciertamente de los recursos financieros de los grandes inversionistas institucionales, la banca internacional, los fondos soberanos, los fondos de pensiones, las sociedades de inversión y, en particular, por su especificidad, de los fondos de inversión inmobiliaria y en infraestructura.

De hecho, la crisis aún vigente en los Estados Unidos y España y antes la del sudeste asiático entre otras - muestran la relación de sus burbujas inmobiliarias con la llegada de capitales extranjeros y otros factores crediticios locales ${ }^{44}$. En la crisis del sudeste asiático de 1997, Marichal ${ }^{45}$ afirma que la cuantiosa entrada de capitales produjo alzas relevantes en los inmuebles en Tailandia, Malasia, Indonesia y Filipinas y también en sus mercados bursátiles, además de una expansión bancaria. La crisis financiera y su complicidad con el real estate fue estrecha ${ }^{46}$.

En América Latina, una investigación relativa a los territorios del capital bancario y previsional en Chile analizó su distribución espacial constatando que "la transferencia geográfica de capitales - que determina la existencia de regiones captadoras y colocadoras netas -revela una no correspondencia entre la geografía financiera y la del producto ${ }^{47}$. Este "desajuste" territorial puede traducirse, concomitantemente con otros factores, en una inflación de precios y en la emergencia de burbujas locales en las regiones captadoras.

En similar sentido, pero ahora respecto del Brasil, Zanin ${ }^{48}$ expresa que la crisis mundial de 2008 afectó el boom inmobiliario de ese país en los años precedentes, boom deudor tanto del crédito inmobiliario como del "billonario" ingreso de capitales extranjeros a las mayores empresas constructoras desde 2005.

Una síntesis de observaciones como las descritas puede expresarse en los siguientes términos: "Uno de los cambios que ha tenido mayor incidencia en la actual revolución urbana es el generado por el aumento de las inversiones inmobiliarias privadas. Este incremento permite afirmar que las ciudades están viviendo una aguda intensificación de la mercantilización de desarrollo urbano"49.

En el mismo documento se expresa que

"el fenómeno solamente puede entenderse en el marco de la creciente movilidad del capital producido por la globalización financiera (en concomitancia con) la aplicación de políticas de liberalización económica, desregulación y apertura externa, (y con las) estrategias de competitividad urbana y city marketing, mediante las cuales las

44 SHILLER, 2009; ROUBINI y MIHM, 2010; STIGLITZ, 2010

45 MARICHAL, 2010

46 HIANG LIOW, 2008

47 DAHER, 1995b: p.55

48 ZANIN, 2011

49 DE MATTOS, 2007: p.83 
autoridades de un número creciente de ciudades buscan, explícita y deliberadamente, atraer capitales externos"

En contextos como los descritos, los fondos inmobiliarios asignan muchas de esas colocaciones diversificando los portafolios $y$, supuestamente, disminuyendo los riesgos para los inversionistas.

"A pesar de las consideraciones de liquidez, las inversiones inmobiliarias puedan ayudar en la diversificación de los portafolios de inversión y reducir la volatilidad por su baja correlación con los activos tradicionales. La creciente necesidad de descorrelación es consistente con la tendencia mundial a incrementar la exposición a inversiones inmobiliarias de los portafolios de inversionistas institucionales: en Estados Unidos y el Reino Unidos ellas representan el 7, 3\% de los mismos"151.

Analizando el comportamiento sectorial y territorial de estos fondos, se reseña, siguiendo a Le Fur ${ }^{52}$ que ellos

"incluyen sociedades de inversiones y sociedades destinadas a generar plusvalías (developer-traders), y que en algunos países invierten sólo en bienes inmobiliarios nacionales (como en Suiza) o en nacionales e internacionales (ej., Países Bajos). ( $Y$ se) agrega que ciertas sociedades invierten sólo en el sector inmobiliario residencial o sólo en el inmobiliario empresarial y otras en ambos. La mitad de tales fondos en 2006 estaban diversificados sectorialmente; un 20\% especializados en el sector inmobiliario comercial, un $16 \%$ en el residencial $y$ un $11 \%$ en el de oficinas. Significativamente, más del $75 \%$ de los fondos efectuaba inversiones inmobiliarias exclusivamente domésticas o locales"153.

En cuanto a la concentración territorial de las colocaciones de los fondos inmobiliarios. Le Fur ${ }^{54}$, revisa la experiencia internacional y verifica que la mayor parte de los Real Estate Investment Trusts (Reits) de los Estados Unidos se especializaba espacial y económicamente; que en Inglaterra las Property Companies localizaban sus inversiones en una región o sector particular (la mayoríaen inmuebles del centro de Londres o en los contornos de la capital); que en Suiza los Fonds de Placement Immobiliers (PPI) especializados en el sector residencial, localizaban sus activos en las cinco ciudades suizas más importantes; y que en Singapur y Hong Kong se constata una concentración relacionada a la restricción de territorio, a la oferta limitada del sector inmobiliario, y a la localización de actividades globales. Todo lo anterior se expresa - en el caso del territorio chino- en que las sociedades inmobiliarias representaban cerca del $40 \%$ de su capitalización bursátil total.

En relación específicamente a los fondos de pensiones suizos, Theurillat, Corpatauxy Crevoisier ${ }^{55}$ comprobaban que casi el $15 \%$ de ellos se invertía en propiedades entre los años 1992-2004.

"Tales fondos disponían de la opción de una gestión directa de compra y administración de sus portafolios de inversión, o bien de adquisición de cuotas o acciones mediante diversos vehículos de inversión. La primera alternativa suponía una cierta dispersión regional en las adquisiciones. En el segundo caso, los fondos eran meros inversionistas con criterios de mercado tales como utilidad, diversificación,

50 DE MATTOS, 2007: p.83

51 ENTORNO \& RETORNO, diciembre 2011

52 LE FUR (2006)

53 DAHER, 2013b: p.12

54 LE FUR, 2006

55 THEURILLAT et al, 2010 
riesgo y liquidez, con un foco concentrado en las principales ciudades del país. Se pasa de una visión de comprar y esperar a otra de comprar y administrar. Un canal puede describirse como directo $y$ no financiarizado $y$ el otro como indirecto $y$ financiarizado. Según tales autores, los fondos de pensiones se han convertido en uno de los principales actores e inversionistas en los mercados inmobiliarios, y sus decisiones resultan decisivas tanto en términos territoriales - comunales, regionales, urbanos - cuanto sectoriales - propiedades comerciales, habitacionales, etc. produciendo o acentuando disparidades espaciales con un impacto en la economía real y en su geografía"

Por su parte, Martin y Minns ${ }^{57}$, analizando la organización espacial y las consecuencias del sistema de fondos de pensiones en Gran Bretaña, encontraron que tales fondos eran controlados y asignados por instituciones financieras del área sudeste del país y, lo que es más crítico, eran invertidos en organismos y compañías de la misma región. Su conclusión es categórica: el sistema de fondos de pensiones, que captaba aportes de las regiones de todo el Reino Unido, centralizaba su administración y localizaba sus inversiones en una región única. En contraste, y en relación a los fondos de pensión de los empleados estatales de Massachusetts, Hagerman, Clarck y Hebb ${ }^{58}$ revelan que por décadas los fondos de pensión de los funcionarios estatales de Massachusetts invierten apostando por el crecimiento económico de su mismo Estado, y lo hacen mayoritariamente en Boston y en ciudades aledañas, beneficiándolas a ellas y a la economía local.

La tendencia verificada en los casos suizo y británico fue igual y tempranamente observada en Chile. En efecto, en un estudio acerca del sesgo concentrador de los fondos de inversión inmobiliaria chilenos - creados por ley en $1989-$ Daher $^{59}$ demostró que un $75 \%$ de sus activos inmobiliarios se orientaba al sector empresarial y el $25 \%$ al habitacional. Constató además que cerca del $90 \%$ de las inversiones se concentraba en la Región Metropolitana y dos terceras partes de la misma se localizaban en sus comunas de más altos ingresos. Cattaneo ${ }^{60}$, en una publicación referida al caso de Santiago de Chile cinco lustros después, expresa conclusiones análogas. Este autor afirma que "el comportamiento del mercado habitacional metropolitano (de Santiago) revela la influencia creciente de las decisiones y de los arbitrajes de los operadores del mercado de capitales sobre este sector", registrando un notorio foco metropolitano de los fondos inmobiliarios, con una clara selectividad espacial en sus inversiones, las que detentan una concentración territorial -en apenas 10 comunas- del 90\%, representando las primeras cinco casi dos tercios del total.

Abundando en el análisis de la concentración, Theurillat ${ }^{61}$ constata que, en medio de un mundo sin fronteras, las instituciones financieras se orientan a proyectos de gran escala en las metrópolis - puesto que las inversiones están muy correlacionadas con la jerarquía urbana - y, dentro de aquéllas, a áreas o distritos específicos.

A propósito de proyectos de gran escala , y observando que los requerimientos de inversión en infraestructura son cada vez mayores y que su financiamiento por el sector privado se ha incrementado alrededor del mundo, Inderst ${ }^{62}$ descubre que también los fondos de pensiones aumentan sus colocaciones en ese rubro - infraestructura social y económica, de transporte y sanitaria- recomendando prudencia frente a su cuantía y rendimiento, y al riesgo asociado a

56 DAHER, 2013b: p.12

57 MARTIN y MINNS, 1995

58 HAGERMAN, CLARCK y HEBB, 2006

59 DAHER, 1995a

${ }^{60}$ CATTANEO, 2011: p.19-20

61 THEURILLAT, 2009

62 INDERST, 2009 
problemas jurídicos, ambientales y políticos. Por su parte, Lorrain (2008), refiriéndose a los fondos de inversión privados- y relacionando la industria financiera con las infraestructuras llegaba a la conclusión de que tales fondos se caracterizaban por el eclecticismo de su portafolio y además por su alta rotación, configurándose en consecuencia como un "conglomerado inestable", dada la nula complementariedad entre las firmas y la relativamente breve temporalidad de permanencia de los activos en su portafolio. Siendo las infraestructuras inversiones de largo plazo y lenta recuperación -vitales tanto para el desarrollo urbano como para la economía nacional y el bienestar social- esa inestabilidad no puede dejar de llamar la atención. Tal vez esa suerte de "volatilidad" de las colocaciones esté vinculada a veces a decisiones de rentabilidad alternativa, y otras veces a los riesgos ya advertidos por Inderst.

Más allá del sector inmobiliario en sentido estricto y del de infraestructuras, pero siempre con proyecciones en el desarrollo urbano, Paulré63 indica que entre las consecuencias del aumento de los fondos de pensiones, reconocidos como causantes de las más relevantes transformaciones del mundo industrial, se incluirían tanto la financiarización de las empresas y -alternativa o complementariamente- de sus estrategias, así como la transformación de sus pautas de gestión, evidenciando una influencia muy incisiva de lógicas esencialmente financieras en su operación e inversiones. Una ilustración de este condicionamiento y de sus efectos territoriales es formulada por Lencioni64, señalando la existencia de una sobredeterminación del capital inmobiliario sobre el industrial, afectando además sus decisiones de localización.

En fin, y esta vez a escala intraurbana, Hidalgo ${ }^{65}$ constata como la transformación de las áreas centrales por los agentes e inversionistas inmobiliarios ha configurado una morfología urbana nueva, con implicaciones socio- espaciales. Pone en relieve, en el caso de Santiago, los planes de repoblamiento vía subsidios, la modernización del comercio, la consolidación de barrios universitarios y bohemios, y también la "latinización" y el resurgimiento de "conventillos" por causa de la inmigración. Estas transformaciones encuentran en las empresas inmobiliarias $-y$, tras ellas, en el sector financiero y en los fondos de inversión- una autoría protagónica, en ocasiones incentivadas por subsidios estatales y normas más permisivas.

\section{Conclusiones}

Las crisis más recientes y más graves y globales, en especial la asiática de los noventa y la subprime que -cinco años después- aún se manifiesta en las economías de muchos países y continentes, han permitido comprobar que los mayores riesgos provienen de los sectores financiero e inmobiliario, y de su articulación, multiplicación y difusión global a través de la financiarización.; impactando así la sustentabilidad urbana y con ella la económica, social y política. Sustentabilidad no sólo local, también nacional e incluso global.

Los fondos de inversión inmobiliaria operando transnacionalmente, junto a los flujos de capital con alta movilidad geográfica y a otros factores globales y locales relacionados con políticas macroeconómicas y en especial monetarias, han resultado ser los causantes, en múltiples ocasiones, de la inflación de burbujas -mediante efecto precio por su alta y selectiva concentración en determinadas metrópolis- que terminan por poner en riesgo no solamente a los propios mercados inmobiliarios y financieros, sino a la economía en su conjunto.

Los fondos de inversión y la financiarización no se limitan al ámbito inmobiliario. No sólo este sector se ha financiarizado: junto a él, también la ciudad ha resultado financiarizada, con las ventajas y, sobre todo, con los riesgos inherentes a esa realidad. La "financiarización urbana" -

\footnotetext{
63 PAULRÉ, 2011

64 LENCIONI, 2011

65 HIDALGO, 2011
} 
más que la inmobiliaria en sentido estricto- es la que se manifiesta desde la crisis "subprime"llamada así en alusión a las hipotecas de la vivienda social para las minorías estadounidenseshasta la crisis española con epicentro en las residencias "superprime" del litoral mediterráneo.

Sin embargo, la relación entre los fondos inmobiliarios y el riesgo urbano es menos obvia y unidireccional: aunque en algún grado el riesgo país y también el riego subnacional urbano con sus especificidades locales- pueden afectar la rentabilidad y recuperación de las inversiones inmobiliarias, en mayor medida el riesgo financiero-inmobiliario termina haciendo más vulnerables las economías urbanas y nacionales en su conjunto y, en extremo, sometiéndolas a crisis más que sectoriales, sistémicas, y más que nacionales, globales.

En otras palabras, es menos vulnerable el sector inmobiliario al riesgo urbano y son más vulnerables las ciudades y los países al riesgo inmobiliario. La sustentabilidad urbana es más dependiente de los sectores financiero e inmobiliario que la sustentabilidad de estos sectores respecto de la economía urbana. La relevancia macroeconómica de tales sectores ha quedado demostrada, más allá de los indicadores estadísticos, en su capacidad de detonar la mayoría de las últimas y más graves crisis globales.

La financiarización, facilitando la multiplicación y dispersión geográfica del riesgo hipotecario y por ende su contagio intersectorial e internacional- ha sido sin duda un factor incremental del riesgo inmobiliario, catalizando las crisis más recientes y haciéndolas más persistentes y generalizadas. La financiarización resolvió, casi paradojalmente, algunas "contradicciones": dio movilidad al capital "in-mueble"; confirió liquidez a su capital "fijo"; hizo divisible su muy imperfecta divisibilidad; y permitió su alta transabilidad a pesar de su esencial condición de "no-transable". Así, las restricciones para una más plena articulación entre los sectores inmobiliario y financiero fueron superadas. Así también, las condiciones que tradicionalmente hacían de las inversiones inmobiliarias una de las más seguras daban paso a otras que multiplicaban su riesgo y el contagio prácticamente universal del mismo.

La demostrada vulnerabilidad del sector financiero y bancario al riesgo inmobiliario-hipotecario, y la propia vulnerabilidad económica nacional y global a dicho riesgo, determinan que la suerte de las economías esté estrechamente vinculada a la suerte de las ciudades, y que la sustentabilidad de aquellas dependa fuertemente de la estabilidad de estas. La alta concentración urbana y, más aún, metropolitana, no sólo de la población, sino también de la economía en su conjunto, y en especial de los sectores financiero e inmobiliario, explica tal dependencia.

Así pues, casi como paradoja, el riesgo supranacional es más dependiente del riesgo subnacional. Aunque las finanzas se han hecho plenamente globales y relativamente ubicuas en términos de flujos más que de inversiones- la economía "real" está cada vez más territorialmente concentrada en un número determinado de grandes ciudades y metrópolis. Por ello, el riesgo global depende en buena medida del metropolitano.

Por cierto no todas las ciudades y ni siquiera todas las metrópolis comparten similarmente esta condición estratégica. Su heterogeneidad y la de sus contextos nacionales e internacionales las hace más o menos protagónicas - por no decir hegemónicas- y, a la vez, más o menos vulnerables o resilientes frente a los impactos de las crisis. Esta heterogeneidad -junto a la competencia internacional e intermetropolitana- está en la base de la selectividad geográfica de las inversiones de los fondos inmobiliarios y de las colocaciones de los demás inversionistas institucionales, incluidos los fondos soberanos y de pensiones. Su fuerte concentración territorial y especialización sectorial agudizan las disparidades territoriales y la inequidad social, a la vez que hacen socialmente más regresivas las trágicas consecuencias de las crisis económicas detonadas con su complicidad. 


\section{Bibliografía}

AALBERS, M (2012). Subprime cities: The political economy of mortgage markets. Malden, MA: Wiley Blackwell.

ATTALI, J. (2009) ¿Y después de la crisis qué...? Propuestas para una nueva democracia mundial. Barcelona: Gedisa.

BORDO, M. \& JEANNE, O. (2002). Boom-busts in asset prices, economic instability, and monetary policy. Working Paper 8966. Cambridge: NBER

BROOKINGS (2010). The state of metropolitan America. Washington DC: Brookings Institution.

CASSIDY, J. (2011). ¿Como os mercados quebran. A lógica das catástrofes econômicas. Rio de Janeiro: Intrínseca.

CATTANEO, R. (2011). Los fondos de inversión inmobiliaria y la producción privada de vivienda en Santiago de Chile. ¿Un nuevo paso hacia la financiarización de la ciudad? EURE, 37 (112), 5-22.

CORPATAUX, J., CREVOISIER, O. \& THEURILLAT, T.(2009). The expansion of the finance industry and its impacts on the economy: a territorial approach based on swiss pension funds. Economic Geography, 85 (3), 313-334.

CORPATAUX, J. \& CREVOISIER, O. (2005). Increased capital mobility/liquidity and its repercussions at regional level: some lessons fron the experiences of Switzerland and UK. European and Urban Regional Studies, 4 (12) 315-334.

DAHER, A. (1995a). Efecto concentrador de los fondos inmobiliarios. Revista de Ciencias Sociales de la U. de Costa Rica, 68, 17-32.

DAHER, A. (1995b) Territorios del capital bancario y previsional. Documents d" Análisis Geográfica, 27,3755.

DAHER, A. (2003). Regiones Commodities. Crisis y contagio en Chile. EURE, XXIX (86), 89-108.

DAHER, A. (2004). Riesgo- país versus riesgo-región: Santiago en el Mercosur. En C.de Mattos et.al. (Eds) Santiago en la globalización: ¿una nueva ciudad? (pp. 85-113). Santiago: Sur/Eure libros.

DAHER, A. (2013 a). El sector inmobiliario y las crisis económicas. EURE, 39 (118): 47-75.

DAHER, A. (2013 b). Territorios de la financiarización urbana y de las crisis inmobiliarias. Revista de Geografía Norte Grande, 56: 7-30.

DE MATTOS, C. (2007). Globalización, negocios inmobiliarios y transformación urbana. Nueva Sociedad , 212, 82-96.

FEDERAL RESERVE SYSTEM (2012). Beige Book (06.06-12) Washington DC: Board of Governors of the Federal Reserve System.

FOSTER, J. y MAGDOFF, F. (2009). La gran crisis financiera: causas y consecuencias. Madrid: Fondo de Cultura Económica.

FUMAGALLI, A. (2011a). Crise econômica global e governanca económico-social. En A. FUMAGALLI y S. MEZZADRA (orgs). A Crise da economia global (pp. 75-105). Río de Janeiro: Civilizacâo Brasileira.

FUMAGALLI, A. (2011b) . Nada será como antes: dez teses sobre a crise financeira. En A. FUMAGALLI y S. MEZZADRA op.cit (pp.321-351). 
HAGERMAN, L., CLARK, G. \& HEBB, T. (2006). Massachusetts Pension Reserves Investment Management Board : urban investing through a transparent selection process. Labor \& Worklife Program. Harvard Law School.

HIANG LIOW, K.(2008). Financial crisis and Asian real estate. Securities market interdependence: some additional evidence. Journal of Property Research, 25 (2), 127-155.

HIDALGO, R. (2011). La transformación de las áreas centrales en América Latina: agentes inmobiliarios y nueva morfología urbana en el caso de Santiago de Chile. En P.C.X. PEREIRA (ed). Negócios imobiliários e transformacôes sócio territoriais en cidades da América Latina (pp. 97-122). Sao Paulo: FAUUSP.

INDERST, G. (2009). Pension fund investment in infrastructure. OECD Working Papers on Insurance and Private Pensions, No 32 . OECD Publishing.

KRUGMAN, P. (2010). De vuelta a la economía de la gran depresión y la crisis del 2008. Bogotá: Norma.

LAEVEN, L. \& VALENCIA, F. (2008). Systemic Banking Crises: a New Database. IMF Working Paper, WP/08/224 International Monetary Fund.

LE FUR, E. (2006). Panorama des fonds immobiliers dans le monde. Management et Avenir 2 (8), 87-116.

LENCIONI, J. (2011). Condominios industriais: um novo nicho dos negócios imobiliários. En P.C.X. PEREIRA (ed.) op.cit. (pp.185-198).

LORRAIN, D. (2008). L'industrie de la finance et les infraestructures: les fonds privés d' investissement. FLUX, 72/73, 138-151.

MANYKA, J. et. al.(2012). Urban America: US cities in the global economy. McKinsey Global Institute.

MARAZZI, C. (2011). A violência do capitalism financeiro. En A. FUMAGALLI y S. MEZZADRA(orgs) op.cit (pp. 23-73).

MARICHAL, C. (2010). Nueva historia de las grandes crisis financieras. Una perspectiva global ,18732008. Buenos Aires: Debate.

MARTIN, R. \& MINNS, R. (1995). Undermining the financial basis of regions: The spatial structure and implications of the UK Pension Fund System. Regional Studies , 29(2), 125-144.

MEZZADRA, S. (2011). Introducâo. En A. FUMAGALLI y S. MEZZADRA (orgs) op cit. (pp.9-21).

NAPPI-CHOULET, I. (1999). Marketing et stratégie de l“immobilier. París : Dunod.

PAULRÉ, B. (2011). Capitalismo cognitivo e financeiracâo dos sistemas económicos. En A. FUMAGALLI y S. MEZZADRA, op cit. (pp. 233-267).

PEREIRA, P.C.X. (2011). Apresentacâo: negócios imobiliários e transformacóes sócio -territoriais em cidades latino americanas: agentes, produtos e segregacáo. En P.C.X. PEREIRA (ed.) op cit. (pp. 7-18).

RAJAN, R. y RANCHARAM, R. (2011). Tierras en venta. Finanzas y Desarrollo ,48 (4), 30-33.

RAMONET, I. (2009). La catástrofe perfecta. Crisis del siglo y refundación del porvenir. Buenos Aires: Capital Intelectual.

REINHART, C. y ROGOFF, K. (2011). Esta vez es distinto: ocho siglos de necedad financiera. México: FCE.

ROUBINI, N. y MIHM, S. (2010). Cómo salimos de ésta. Santiago: Destino.

SHILLER, R. (2007). Historic turning points in real estate. Discussion Paper, $n^{\circ} 1610$. Cowles Foundation for Research in Economics. New Haven: Yale University.

_ (2009). El estallido de la burbuja. Cómo se llegó a la crisis y como salir de ella. Barcelona: Gestión 2000. 
SOROS, G. (2008). El nuevo paradigma de los mercados financieros. Para entender la crisis económica actual. Buenos Aires: Taurus.

STIGLITZ, J. (2010). Caída libre. El libre mercado y el hundimiento de la economía mundial. Buenos Aires: Taurus.

TAMAMES, R. (2009). La crisis financiera internacional .Análisis y soluciones. Buenos Aires: Edaf.

THEURILLAT, T. (2009). The negotiated city: between financialisation and sustainability. Research Group in Territorial Economy. University of Neuchätel.

THEURILLAT, T., CORPATAUX, J. \& CREVOISIER, O. (2010). Property sector financialisation: the case of swiss pensions funds (1992-2005). European Planning Studies,18 (2), 189-212.

ZANIN, L. (2011). Cidades medias carimbadas: a producâo imobiliária por empresas construtoras de capital aberto. En P.C.X. Pereira (Ed.) op.cit. (pp. 49-72). 